\title{
Autotransplantation of the lung in sheep
}

\author{
L. G. DAVIES, T. H. L. ROSSER, AND L.R. WEST \\ From Sully Hospital, Sully, Penarth, Glamorgan
}

Since the pioneer work of Demikhov (1962), Staudacher, Bellinazzo, and Pulin (1950), and Juvenelle, Citret, Wiles, and Stewart (1951), the possibilities and problems of lung transplantation have received increasing attention, and indeed homotransplantation has already been attempted in man (Hardy, Webb, Dalton, and Walker, 1963b ; Magovern and Yates, 1964). Before transplantation of a lung becomes a generally acceptable method of treating patients with respiratory disease, there are three problems or groups of problems which must be overcome. First, the technical problems of inserting or implanting a lung must be understood and mastered. Secondly, there is the immunological barrier, and thirdly the supply and preservation of suitable lungs.

This paper is concerned solely with the first problem, the technical difficulties of implantation and their relation to the subsequent function of the implanted lung. Autotransplantation, where the lung is removed and then reimplanted, is the ideal way to examine this problem, since it avoids the immunological reaction. Other workers (Blumenstock and Kahn, 1961 ; Hardy, Eraslan, and Dalton, 1963a ; Reemtsma, Rogers, Lucas, Schmidt, and Davis, 1963) have reported their experience with autotransplantation of a lung in the $\mathrm{dog}$, and the techniques of operation are already well documented. Autograft function may return to normal, but it is more usual for there to be some reduction, and this is often considerable. The reasons do not seem to be understood and we thought the problem demanded particular study. Certainly the reported variation in autograft function suggested an avoidable cause, and we were reluctant to believe that the procedure itself necessarily led to impaired pulmonary function.

MATERIAL AND METHODS

Experiments were performed in 40 ewe sheep, and in each the left lung was removed and then reimplanted. The weight of these animals ranged from 32 to $75 \mathrm{~kg}$. (mean $48 \mathrm{~kg}$.) and the estimated age from 6 months to 10 years (mean about 3 years). Previous vaccination with Covexin ${ }^{1}$ had given protection from the common endemic clostridial infections. In 17 of these animals, bronchospirometry with a modified Carlens catheter was performed some weeks before operation in order to measure the normal differential lung function.

The animals were anaesthetized with 300 to 500 $\mathrm{mg}$. of thiopentone and 50 to $75 \mathrm{mg}$. of succinylcholine chloride injected intravenously ; a cuffed endotracheal tube was inserted and ventilation was maintained with a Starling pump. The anaesthetic mixture was halothane (usually $1 \%$ ) in equal parts of oxygen and air. The minute volume was estimated from a previously obtained nomogram relating body weight to ventilation, and, if necessary, adjustments were made after the analysis of arterial samples withdrawn from a brachial artery through a fine nylon catheter. Arterial saturation was measured with a Kipp Hemoreflector and the $p \mathrm{H}$ and $\mathrm{PCO}_{2}$ with a Micro Astrup.

A left lateral thoracotomy was made in each case through the fifth intercostal space; the pulmonary ligament was divided and the structures at the hilum were dissected. The bronchial artery was ligatted and the left main bronchus and left pulmonary artery were taped. The pericardium was opened and the left azygos vein, which in the sheep enters the coronary sinus, was dissected, divided, and reflected. The-two left pulmonary veins and the adjacent left atrium were cleaned of fat, and then heparin $(1.5 \mathrm{mg}$. $/ \mathrm{kg}$.) was given intravenously. During this preparatory work the lung,was carefully reinflated at intervals by intermittent obstruction of the expiratory valve. With the lung fulky inflated a Price-Thomas bronchial clamp was*applied to the left main bronchus very çlose to its origin, and the bronchus was divided with a scalpel just beyond the clamp. The left pulmonary artery was then occluded with a small Pott's clamp and divided, the distal segment being controlled with a tape. A Satinsky clamp was then applied to the left atrium in such a way that an adequate cuff of atrial wall could be removed with the pulmonary veins, but care was necessary to avoid obstructing the right inferior pulmonary vein. The atrium was then divided with curved scissors, the veins being occluded with tapes (Fig. 1). Any secretions in the air passages were aspirated, and $20 \mathrm{ml}$. of normal saline

${ }^{1}$ Burroughs and Wellcome 


\section{LEFT MAIN BRONCHUS LEFT PULMONARY ARTERY LEFT SUPERIOR AND INFERIOR PULMONARY VEINS}

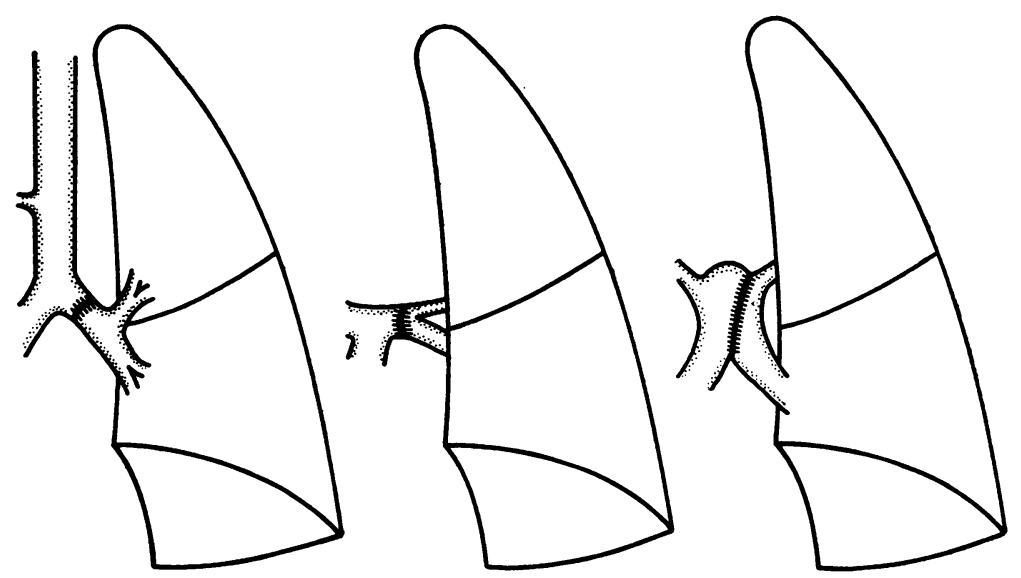

FIG. 1. Tracheo-bronchial anatomy in the sheep and sites of division of the hilar structures.

containing a little heparin (1,000 units in $500 \mathrm{ml}$. of normal saline) was injected into the left pulmonary artery and then the tape was reapplied.

Reimplantation then began with the bronchus, using interrupted sutures of 0000 silk and without reinforcing tissue. The left pulmonary artery was next repaired with a continuous suture of 0000 silk. Finally the left atrial cuff was anastomosed with a simple continuous suture of 0000 silk. There is insufficient tissue for everting sutures.

When the anastomoses had been completed, the clamp was first removed from the bronchus and blood or secretions were removed immediately by aspiration. The lung was then gently reinflated, and the clamps on the left atrium and pulmonary artery were released. It was sometimes necessary to insert interrupted sutures to reinforce the atrial repair. Once haemostasis was satisfactory, the chest was closed in layers with catgut, and two pleural drainage tubes were inserted. Heparin reversal was never necessary. Occasionally fresh ACD blood collected from other sheep was given as an intravenous drip during operation, but generally blood loss was small and dextran (up to $500 \mathrm{ml}$.) was quite adequate. The animals were nursed in the supine position in the immediate post-operative period until air leaks and drainage had ceased (usually six to eight hours), then the tubes were removed and the sheep were returned to the pen. Antibiotics (500,000 units of penicillin and $0.5 \mathrm{~g}$. of streptomycin) were given daily for a week and then the animals went back to the field.

In the long-term survivors, pulmonary function was assessed at three months by bronchospirometry. In the sheep the right upper lobe bronchus joins the trachea directly and the left main bronchus is relatively short. Because of these anatomical variations and the surprising length of the trachea, the Carlens catheter had to be modified. After preliminary sedation with 5 to $15 \mathrm{ml}$. of veterinary nembutal, the cords and trachea were sprayed with $4 \%$ lignocaine before the catheter was introduced. The investigation required the sheep to be in the supine position, and we found screening control with an image intensifier essential to ensure that the left main bronchus had been entered. Moreover the correct position was critical, and if the initial tracings appeared to indicate a reduced function on the left side the catheter was withdrawn slightly and a further record was obtained, for sometimes the distal cuff occluded the orifice of the left upper lobe bronchus. This investigation was repeated at six, 12 , and 18 months.

Bronchography was performed immediately afterwards, injecting 20 to $40 \mathrm{ml}$. of propyliodone into the left main bronchus through a catheter and under screening control. Films were obtained in lateral and P.A. positions; occasionally an oblique view was recorded.

At six months the pulmonary circulation was studied by cardiac catheterization, the right heart pressures were measured, and the effect of temporary occlusion of the right and left pulmonary arteries was studied. Angiography was then performed injecting contrast $(85 \%$ sodium diatrizoate, $1 \mathrm{mg} . / \mathrm{kg}$.) into the main pulmonary artery just above the valve, with the animal at $45^{\circ}$ left anterior oblique and obtaining single films or a cine film.

During this follow-up period the survivors formed part of a flock which led a natural out-of-doors existence in all weathers, and most of them have lambed. Close daily observation was not of course possible at this stage and in most instances it proved unnecessary. 
Post-mortem examinations were carried out as early as possible on all the animals that died after operation. After examining the pleura, the heart and lungs were removed together and, where appropriate, the lungs were inflated and photographed. We paid particular attention to the state of the pulmonary veins on the operated side and found post-mortem angiography the best method of study. First the left atrial appendage was incised and as much clot as possible was removed from the left atrium and adjacent pulmonary veins. A rubber catheter was then inserted into the left atrium and tied in place. Contrast medium (micropaque) was injected under screening control until the right pulmonary veins filled normally and the state of the left was revealed.

The lungs were then inflated and fixed with formalin in the usual way, and the suture lines were examined later by dissection. The cut surfaces of the lungs were examined macroscopically after fixation, and representative portions were removed for histological examination.

\section{RESULTS}

Three sheep died during operation, one from irreversible ventricular fibrillation provoked by dissection of the left atrium, a second as a result of haemorrhage from a torn pulmonary artery, and the third of asphyxia due to an anaesthetic mishap.

EARLY POST-OPERATIVE MORTALITY The early post-operative mortality was heavy (Table I); it was over $40 \%$, and most of the deaths occurred within the first six hours. The main cause was pulmonary venous obstruction, and this produced a dramatic clinical picture with pulmonary oedema, increasing dyspnoea, a falling arterial oxygen saturation, and death from asphyxia. Auscultation in these animals revealed the usual

TABLE I

EARLY POST-OPERATIVE MORTALITY $42 \%$

\begin{tabular}{|c|c|c|}
\hline $\begin{array}{l}\text { Experiment } \\
\text { No. }\end{array}$ & $\underset{\text { Time }}{\text { Survival }}$ & Cause of Death \\
\hline $\begin{array}{l}\text { T } 7 \\
\text { T10 } \\
\text { T11 } \\
\text { T12 } \\
\text { T16 } \\
\text { T18 } \\
\text { T26 } \\
\text { T27 } \\
\text { T30 }\end{array}$ & $\begin{array}{l}6 \text { hours } \\
1 \text { hour } \\
1 \text { hour } \\
8 \text { hours } \\
2 \text { weeks } \\
1 \text { hour } \\
6 \text { days } \\
5 \text { hours } \\
4 \text { hours }\end{array}$ & $\begin{array}{l}\text { Bilateral pneumothorax } \\
\text { Asphyxia } \\
\text { Haemothorax } \\
\text { Asphyxia (clot in bronchus) } \\
\text { Pulmonary venous obstruction } \\
\text { Pulmonary venous obstruction } \\
\text { Haemothorax } \\
\text { Pulmonary venous obstruction } \\
\text { Haemothorax and pulmonary venous } \\
\text { obstruction }\end{array}$ \\
\hline $\begin{array}{l}\text { T31 } \\
\text { T34 } \\
\text { T36 } \\
\text { T40 } \\
\text { T42 } \\
\text { T44 } \\
\text { T45 } \\
\text { T48 }\end{array}$ & $\begin{array}{l}6 \text { hours } \\
2 \text { days } \\
4 \text { hours } \\
2 \text { hours } \\
6 \text { hours } \\
4 \text { days } \\
7 \text { hours } \\
3 \text { hours }\end{array}$ & $\begin{array}{l}\text { Pulmonary venous obstruction } \\
\text { Asphyxia } \\
\text { Haemothorax } \\
\text { Pulmonary venous obstruction } \\
\text { Pulmonary venous obstruction } \\
\text { Pulmonary venous obstruction } \\
\text { (Swab) Pulmonary venous obstruction } \\
\text { Pulmonary venous obstruction }\end{array}$ \\
\hline
\end{tabular}

signs of pulmonary oedema. At necropsy the affected lobe or lung was intensely haemorrhagic and heavy with lesser changes in the right lung (Figs $2 \mathrm{a}$ and $\mathrm{b}$ ).

Figures $3 a$ and $b$ show examples of post-mortem angiograms of the left atrium and pulmonary veins of sheep which died in this way. This investigation and later dissection revealed no specimen with thrombotic obstruction unless there was already severe narrowing of the left atrium or pulmonary vein by the suture line. Obstruction did not have to be complete to cause pulmonary oedema; sometimes severe stenosis was found. In this group there were seven sheep in which both left pulmonary veins were obstructed or severely stenosed, two in which the inferior vein alone and one in which the superior vein alone were obstructed.

In one animal a swab had been accidentally left overlying the atrial suture line, and this could have contributed to pulmonary venous obstruction. Stenosis can be avoided. Fig. $4 \mathrm{a}$ is an example where both superior and inferior pulmonary veins are normally patent; Fig. 4b shows complete occlusion of a superior lobe vein, but the inferior vein is normal.

The second commonest cause of death in this group was haemorrhage, probably from the atrial suture line.

LATE POST-OPERATIVE MORTALITY Six sheep died between one and three months after operation (Table II). In four of these the cause was pulmonary venous obstruction, but the clinical picture was different; pulmonary infection was the presenting feature. This is of considerable interest, for these animals escaped fatal pulmonary oedema even though the venous obstruction may have been severe from the time of operation (Fig. 5).

LONG-TERM SURVIVORS This left 14 animals $(35 \%)$ which were long-term survivors, and unfortunately some of these have died of unrelated

T A B LE II

LATE POST-OPERATIVE MORTALITY $15 \%$

\begin{tabular}{|c|c|c|}
\hline $\begin{array}{l}\text { Experiment } \\
\text { No. }\end{array}$ & $\underset{\text { Time }}{\text { Survival }}$ & Cause of Death \\
\hline T 8 & 3 months & Pulmonary venous obstruction and \\
\hline T 9 & 7 weeks & $\begin{array}{l}\text { pulmonary venous obstruction and } \\
\text { Pulmoury }\end{array}$ \\
\hline $\begin{array}{l}\text { T13 } \\
\text { T14 } \\
\text { T17 }\end{array}$ & $\begin{array}{l}10 \text { weeks } \\
1 \text { month } \\
1 \text { month }\end{array}$ & $\begin{array}{l}\text { Pulmonary venous obstruction } \\
\text { Cerebral damage (anaesthetic asphyxia) } \\
\text { Pulmonary venous obstruction and }\end{array}$ \\
\hline T33 & 1 month & Pneumonia after bronchospirometry \\
\hline
\end{tabular}




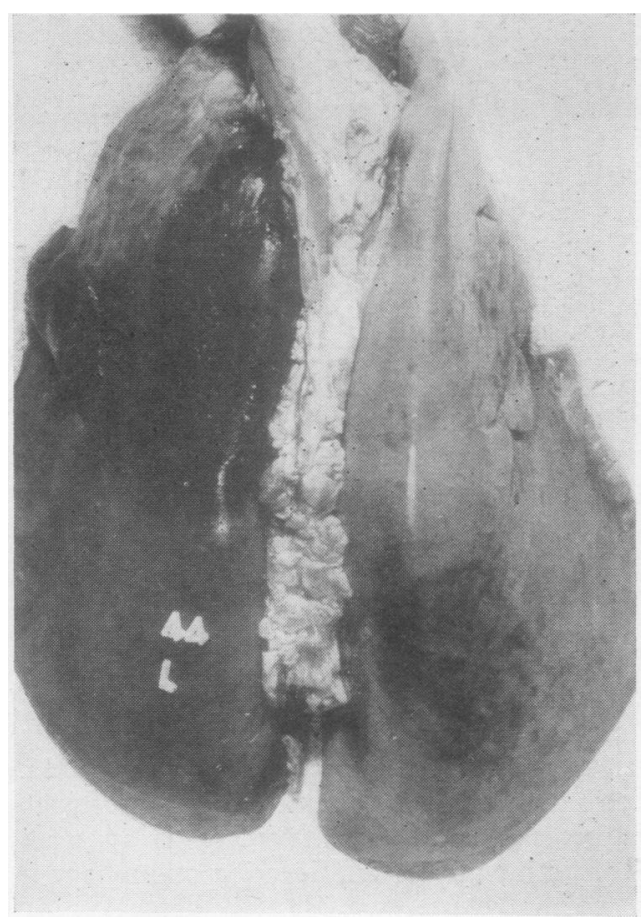

FIG. 2a. External appearance of infarcted left upper lobe due to obstruction of superior pulmonary vein.

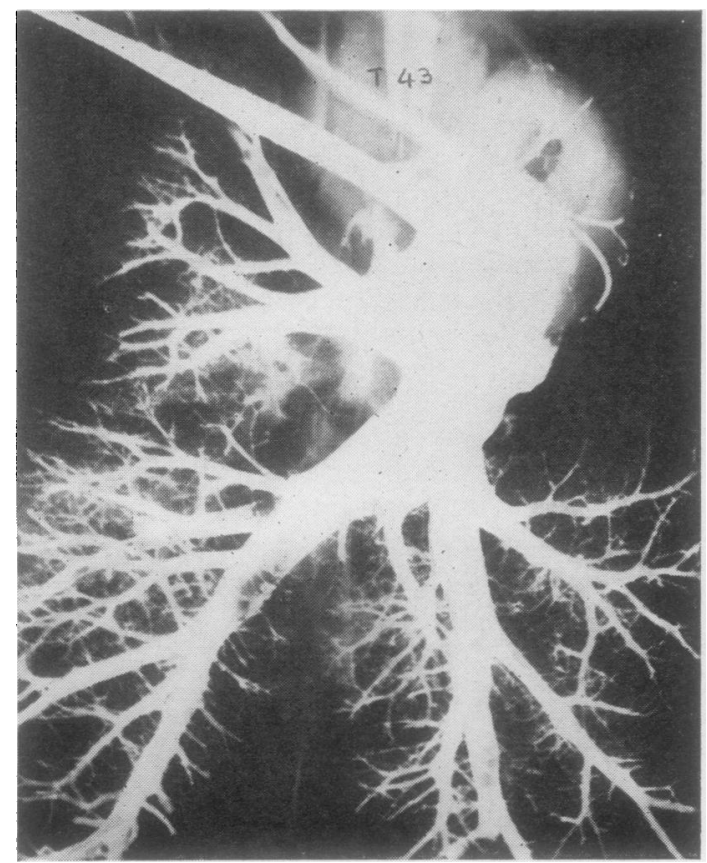

FIG. 3a. Injected specimen shows complete occlusion of left superior vein with normal filling of left inferior vein.

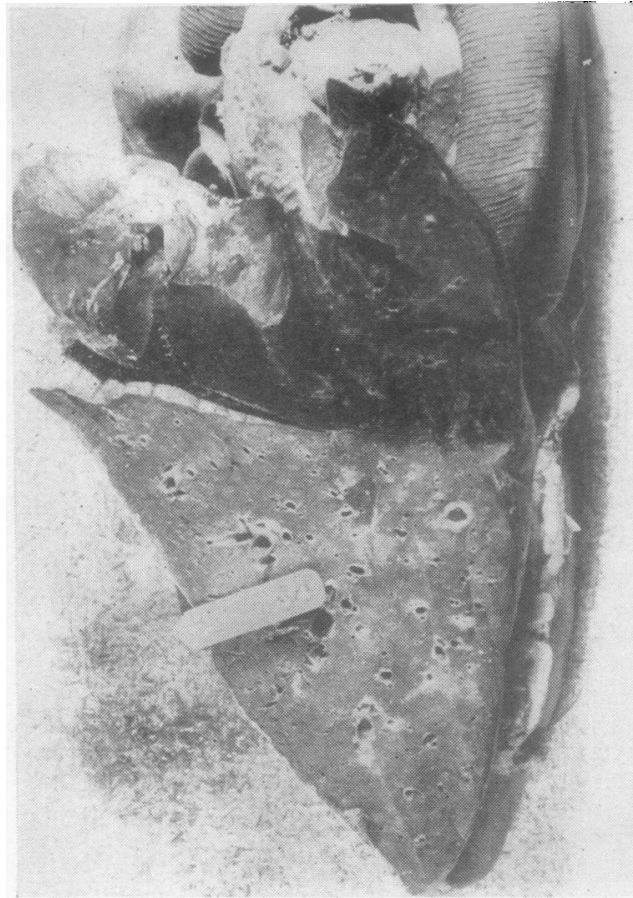

FIG. 2b. Cut surface of left lung.

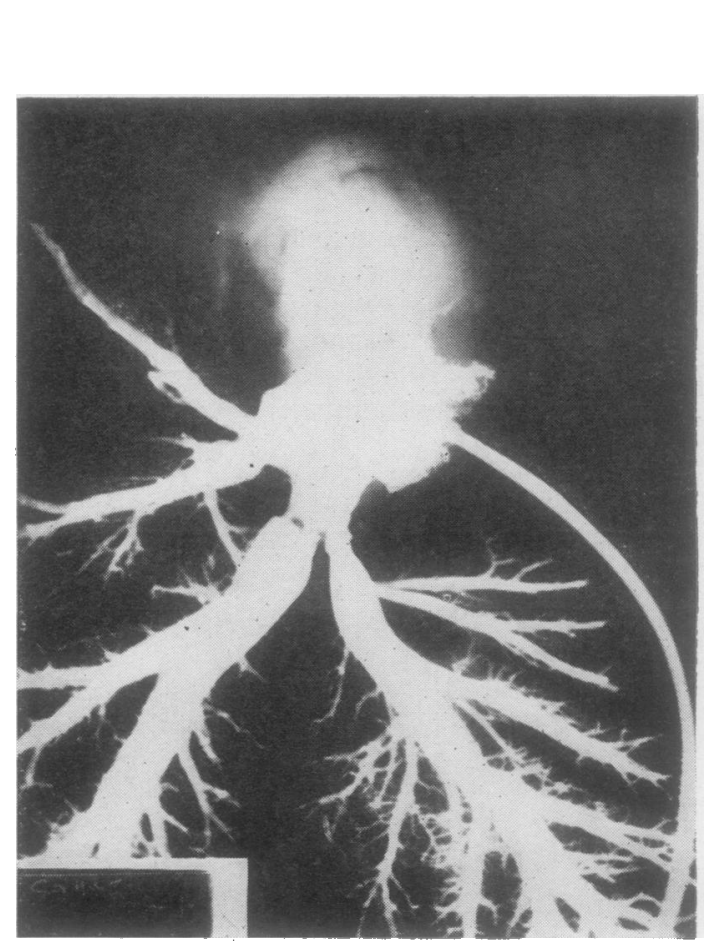

FIG. 3b. Complete occlusion of left superior vein and narrowing of left inferior vein. 


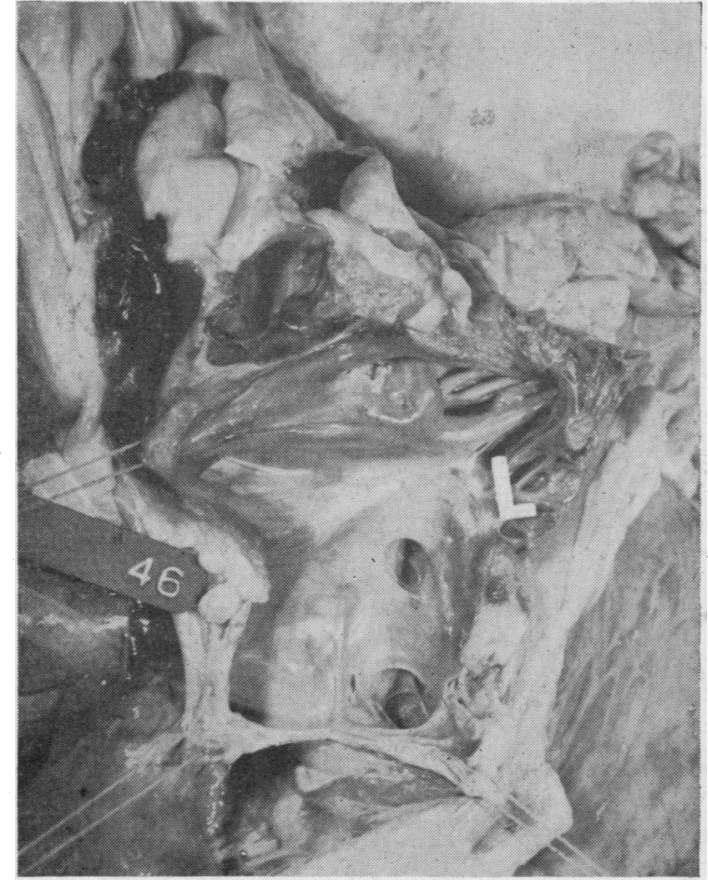

FIG. 4a. Left atrium nine months after operation in a sheep which died of unrelated disease. Both superior and inferior pulmonary veins are normally patent.

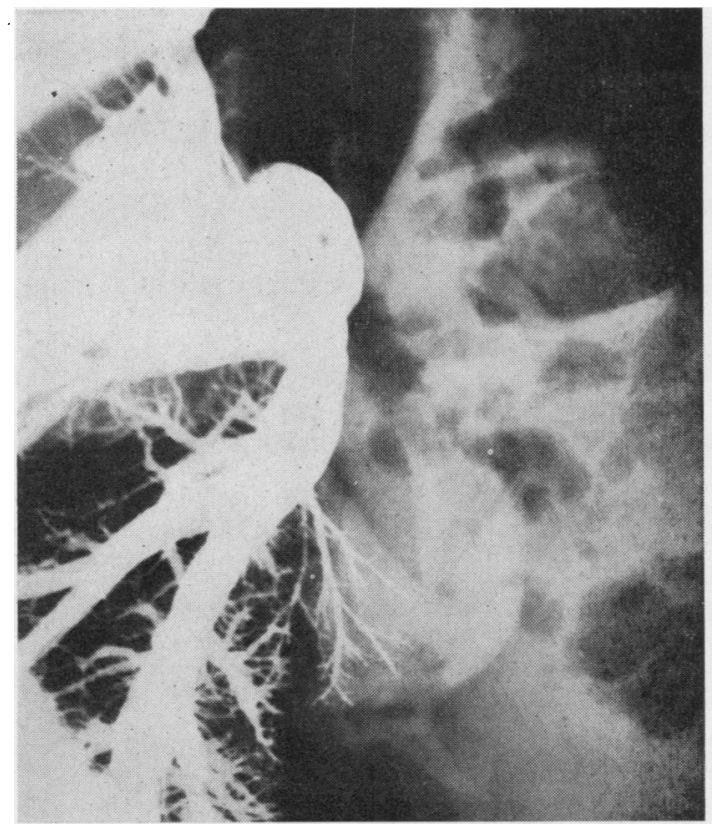

FIG. 5. An injected necropsy specimen showing complete obstruction of the left pulmonary veins with abscess cavities in the infected left lung.

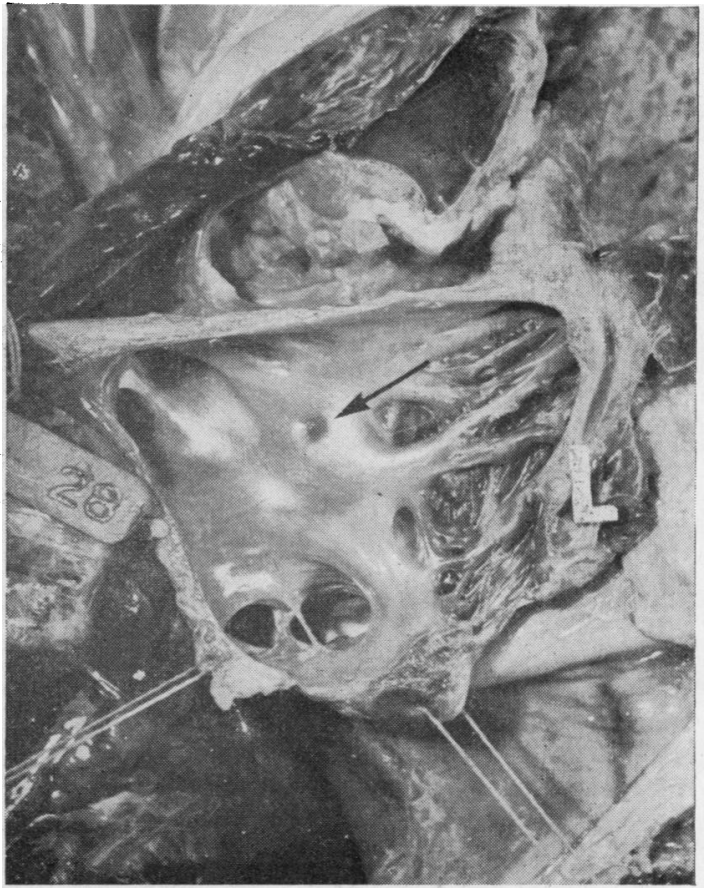

FIG. 4b. Left atrium 17 months after operation in a sheep which died of unrelated disease. There is complete occlusion of the superior pulmonary vein (indicated by arrow), whereas the inferior vein is normally patent.

disease (Table III). The period of survival ranges from two to 20 months and the animals appear fit and well. In Table III is our estimate of the state of the left lung, and this is based on the following investigations.

P.A. chest films Radiographs were obtained routinely at three, six, 12 , and 18 months. The deep antero-posterior diameter of the thorax

T ABLE III

SURVTVORS, $35 \%$

\begin{tabular}{l|r|l}
\hline $\begin{array}{c}\text { Experiment } \\
\text { No. }\end{array}$ & $\begin{array}{c}\text { Survival } \\
\text { Time } \\
\text { (months) }\end{array}$ & State of Autograft Function \\
\hline T 5 & 20 & Impaired; obstetric death \\
T 6 & 6 & Impaired; intestinal obstruction \\
T15 & 9 & Normal; septicaemia \\
T21 & 16 & Normal \\
T22 & 16 & Normal \\
T24 & 16 & Impaired \\
T28 & 15 & Normal \\
T32 & 3 & Not yet studied \\
T38 & 14 & Impaired \\
T39 & 12 & Impaired \\
T43 & 8 & Normal; obstetric death \\
T46 & 6 & Normal \\
T47 & 6 & Normal anaesthetic death \\
T50 & 2 & Not yet studied \\
\hline
\end{tabular}




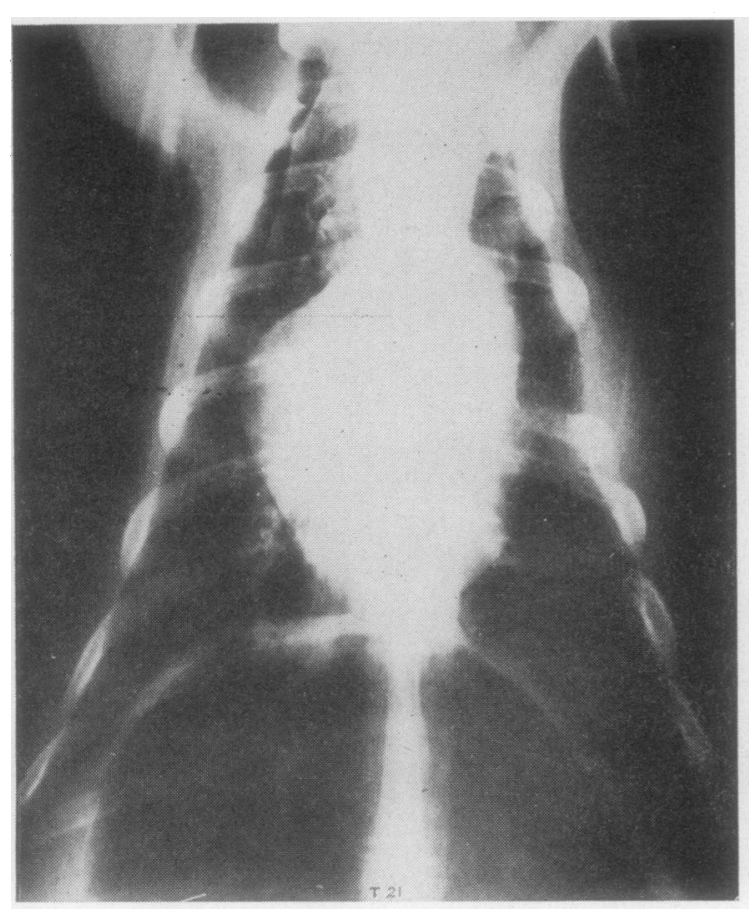

(a)

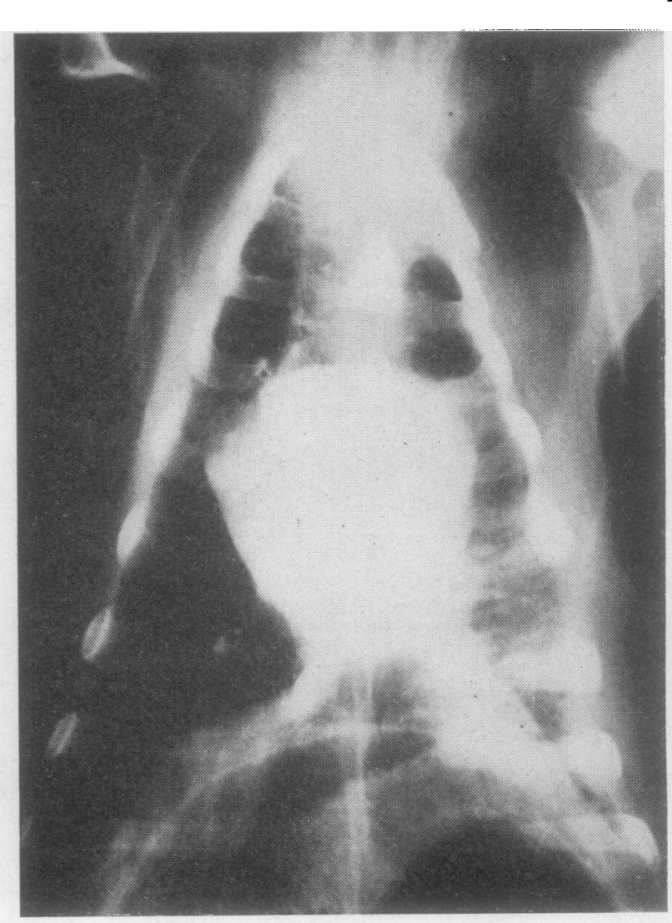

(b)

FIG. 6. (a) Radiograph showing complete re-expansion of the left lung. (b) Left pleural thickening probably caused by a post-operative haemothorax. Both films were taken six months after operation.

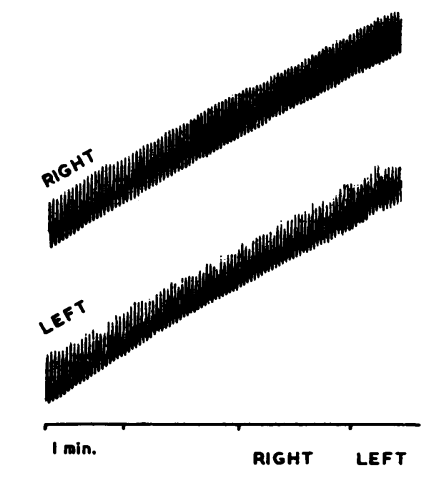

$\mathrm{O}_{2}$ Consumption mL/min.....170 [50\%]170 [50\%]

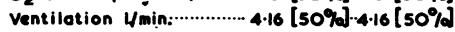
BRONCHOSPIROMETRY 6 MONTHS AFTER AUTOTRANSPLANTATION OF LEFT LUNG
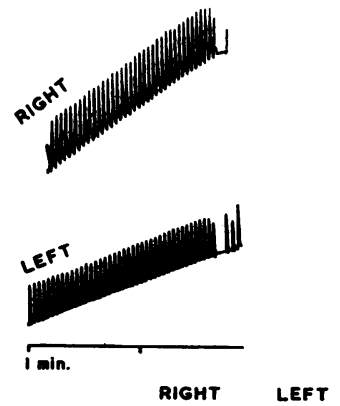

O Consumption mL/min...205 [66\%]-105 [34\%] ventilation Lain................4.0 [59\%.-2.75[41\%] BRONCHOSPIROMETRY 12 MONTHS AFTER AUTOTRANSPLANTATION
OF LEFT LUNG

FIG. 7a. An example of a normally functioning autograft. Exp. T 46; a 4-year-old ewe weighing $59 \mathrm{~kg}$.

FIG. 7b. Impairment of left lung function after auto- $\frac{\mathbb{\mathrm { D }}}{2}$ transplantation. Exp. T38; a 2-year-old ewe weighing $46 \mathrm{~kg}$. 
makes it more difficult to obtain good films in sheep than in man. Nevertheless adequate radiographs can be obtained with the animal supine and sedated. These films are often a helpful guide to the state of the autograft ; for example, Fig. 6a shows a normal diaphragm and costophrenic angle and clear lung fields: this suggests a good result. In contrast, Fig. $6 \mathrm{~b}$ shows changes we attributed to the late result of a haemothorax, and ventilation was a little reduced on this side.

Bronchospirometry The results of this investigation in 17 normal sheep before operation are shown in Table IV, and it will be seen that the lungs share equally in ventilation and oxygen uptake. As this investigation can be rather traumatic we made no measurements in the immediate post-operative period. The earliest record obtained was at one month, but all were studied at three months and at intervals after this. Figure 7a shows an example of one of our best results with both ventilation and oxygen uptake in the reimplanted left lung normal. In contrast, Fig. $7 \mathrm{~b}$ is a tracing from one of the more disappointing results, and it will be seen that both ventilation and oxygen uptake of the left lung are reduced. Figure 8 shows diagrammatically the results of this investigation in 11 long-term survivors. The mean ventilation of the left lung is only slightly reduced (48\%), and this we have attributed to the effect of the thoracotomy. But the oxygen consumption
TABLE IV

BRONCHOSPIROMETRY IN 17 SHEEP BEFORE OPERATION

\begin{tabular}{|c|c|c|c|c|c|c|c|c|}
\hline \multirow{2}{*}{ Sheep } & \multicolumn{4}{|c|}{ Ventilation (1.'min.) } & \multicolumn{4}{|c|}{ Oxygen Uptake (ml. 'min). } \\
\hline & \multicolumn{2}{|c|}{ Right Lung } & \multicolumn{2}{|c|}{ Left Lung } & \multicolumn{2}{|c|}{ Right Lung } & \multicolumn{2}{|c|}{ Left Lung } \\
\hline $\begin{array}{l}\text { T14 } \\
\text { T27 } \\
\text { T29 } \\
\text { T32 } \\
\text { T33 } \\
\text { T34 } \\
\text { T36 } \\
\text { T38 } \\
\text { T39 } \\
\text { T40 } \\
\text { T42 } \\
\text { T43 } \\
\text { T44 } \\
\text { T45 } \\
\text { T47 } \\
\text { T48 }\end{array}$ & $\begin{array}{l}3 \cdot 57 \\
4 \cdot 76 \\
5.72 \\
5 \cdot 2 \\
2 \cdot 34 \\
7 \cdot 20 \\
1.65 \\
3 \cdot 38 \\
3 \cdot 0 \\
2 \cdot 86 \\
2 \cdot 40 \\
4 \cdot 18 \\
3 \cdot 30 \\
3 \cdot 20 \\
3 \cdot 36 \\
4 \cdot 55 \\
4 \cdot 18\end{array}$ & $\begin{array}{l}(\%) \\
50 \\
50 \\
47 \\
50 \\
48 \\
50 \\
46 \\
56 \\
56 \\
46 \\
46 \\
50 \\
54 \\
47 \\
48 \\
48\end{array}$ & $\begin{array}{l}3.57 \\
4.76 \\
6.50 \\
5.2 \\
2.52 \\
7.20 \\
1.95 \\
2.60 \\
2.37 \\
3.38 \\
2.88 \\
4.18 \\
2.85 \\
3.60 \\
3.64 \\
4.90\end{array}$ & $\begin{array}{c}\% \%) \\
50 \\
50 \\
53 \\
50 \\
52 \\
50 \\
54 \\
43 \\
44 \\
54 \\
54 \\
50 \\
46 \\
53 \\
52 \\
52\end{array}$ & $\begin{array}{r}40 \\
140 \\
175 \\
150 \\
95 \\
130 \\
90 \\
77 \\
90 \\
107 \\
95 \\
120 \\
103 \\
80 \\
105\end{array}$ & $\begin{array}{c}(\%) \\
51 \\
52 \\
51 \\
50 \\
51 \\
50 \\
50 \\
45 \\
53 \\
49 \\
49 \\
50 \\
51 \\
47 \\
48 \\
45 \\
51\end{array}$ & $\begin{array}{r}137 \\
130 \\
165 \\
150 \\
90 \\
130 \\
90 \\
93 \\
80 \\
113 \\
100 \\
120 \\
97 \\
90 \\
115 \\
135 \\
107\end{array}$ & $\begin{array}{c}(\%) \\
49 \\
48 \\
49 \\
50 \\
49 \\
50 \\
50 \\
55 \\
47\end{array}$ \\
\hline & 3.81 & & 3.88 & $50 \cdot 4$ & 112.7 & $49 \cdot 6$ & $114 \cdot 1$ & 50 \\
\hline
\end{tabular}

measurements show a different pattern and range between normal (50\%) and $20 \%$, which is a gross reduction: the mean oxygen uptake is in fact $41 \%$. These results resemble those reported by other workers, and we believe we can show the cause to be a change in the pulmonary circulation which may follow operation.

Angiography Angiograms which outline and allow comparison of the left and right branches of the pulmonary artery were obtained in 10 sheep and have been helpful. Figure 9 is an ex-
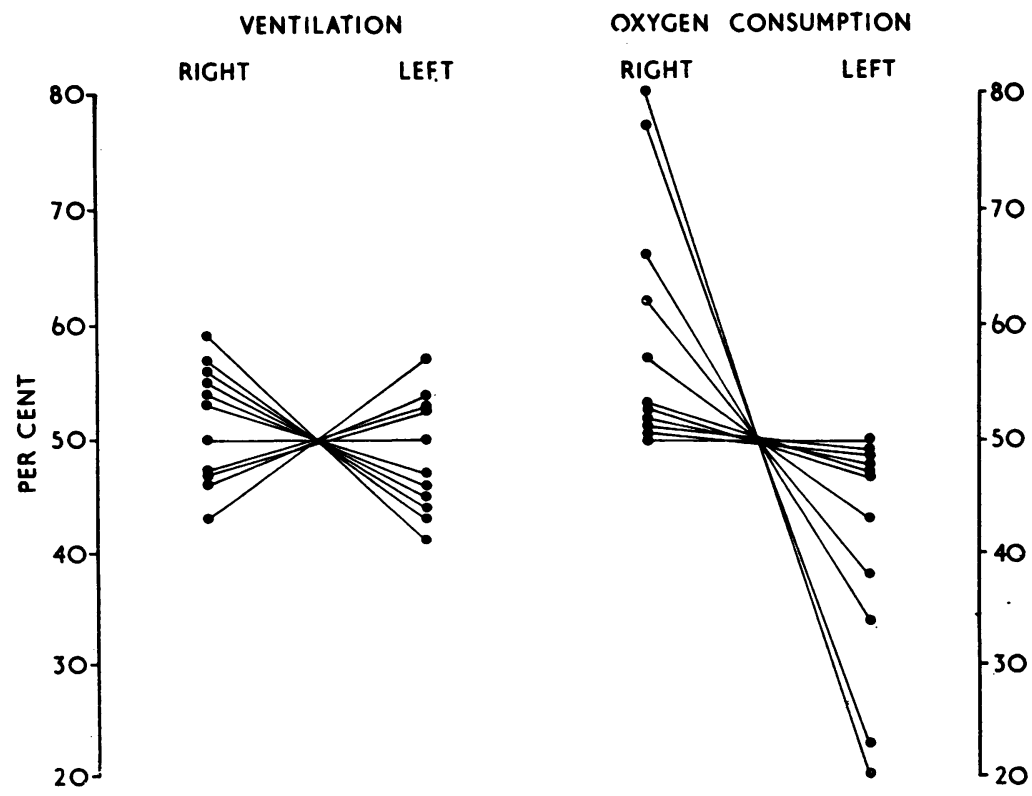

FIG. 8. Bronchospirometry six months after operation in 11 long-term survivors. The ventilation measurements are all normal or near normal. There is a much wider variation in the oxygen consumption figures. 
ample and shows the most marked narrowing which the suture line produced in the left pulmonary artery. But equal amounts of contrast are entering each lung; the main branches are of normal size and so are the secondary branches. In this particular sheep no pressure gradient could be recorded across this suture line, nor indeed was any murmur audible. The evidence therefore is that in these sheep the narrowing which may follow the division and suture of the left pulmonary artery was never severe enough to reduce the blood flow into the left lung. Even in one sheep in which the normal alignment of the proximal and distal segments of the pulmonary artery was lost and suturing resulted in a kinked left pulmonary artery (Fig. 10) there appeared to be no reduction in blood flow into the left lung.

However, there were some sheep in which the left pulmonary artery appeared to be smaller than the right (Fig. 11), and the difference was also reflected in the secondary branches. We interpreted this as indicating preferential blood flow into the right lung, but this is not the result of the division and repair of the left pulmonary artery.

Cardiac catheterization This was carried out in nine survivors, and the pulmonary artery pressures

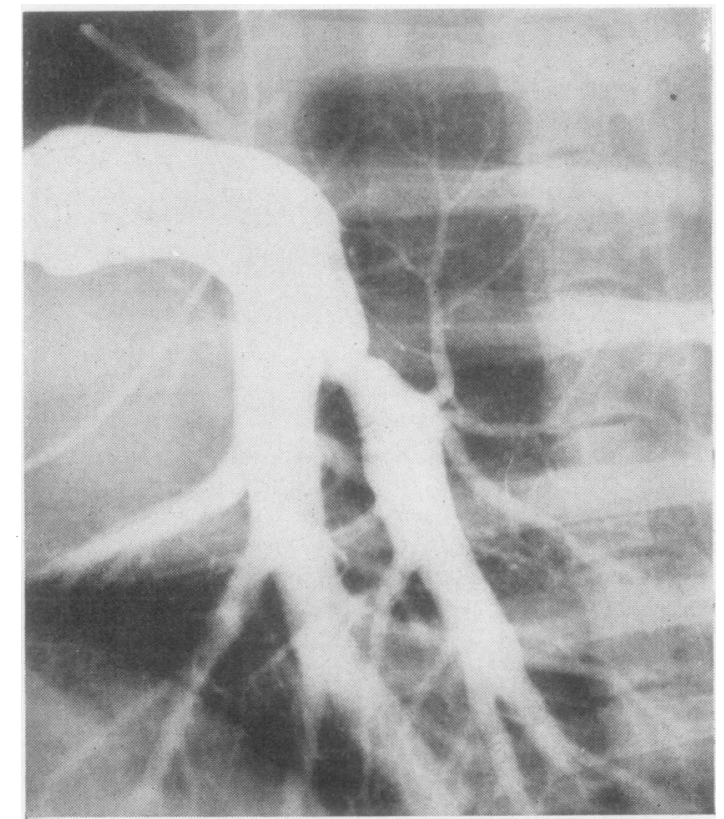

FIG. 9. Pulmonary artery angiogram showing narrowing at the anastomosis. The vessel beyond is of normal calibre and so are the secondary branches.

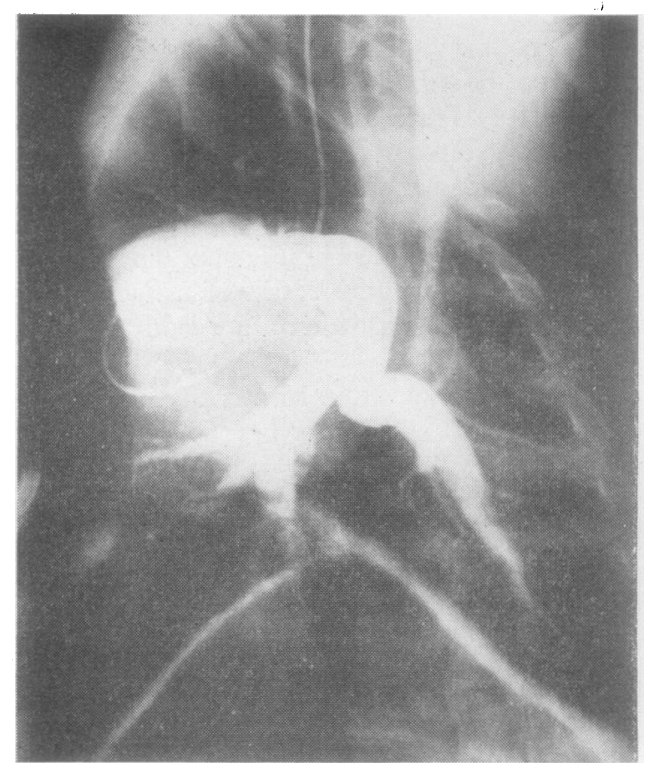

FIG. 10. Angiogram showing kinking of left pulmonary artery; the normal alignment was lost during the anastomosis.

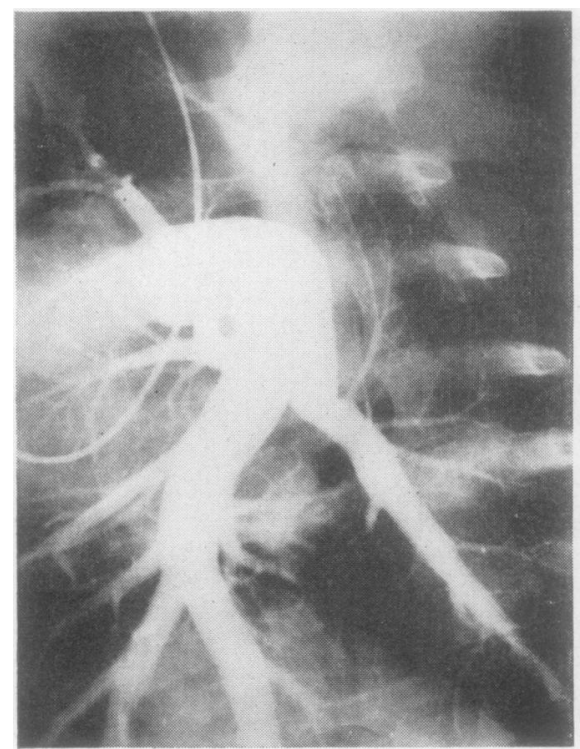

FIG. 11. Pulmonary angiogram showing that the right and $\stackrel{\odot}{\stackrel{\odot}{\odot}}$ left main branches are of unequal size. The left is reduced $\triangle$ and the right dilated, indicating preferential blood flow. 


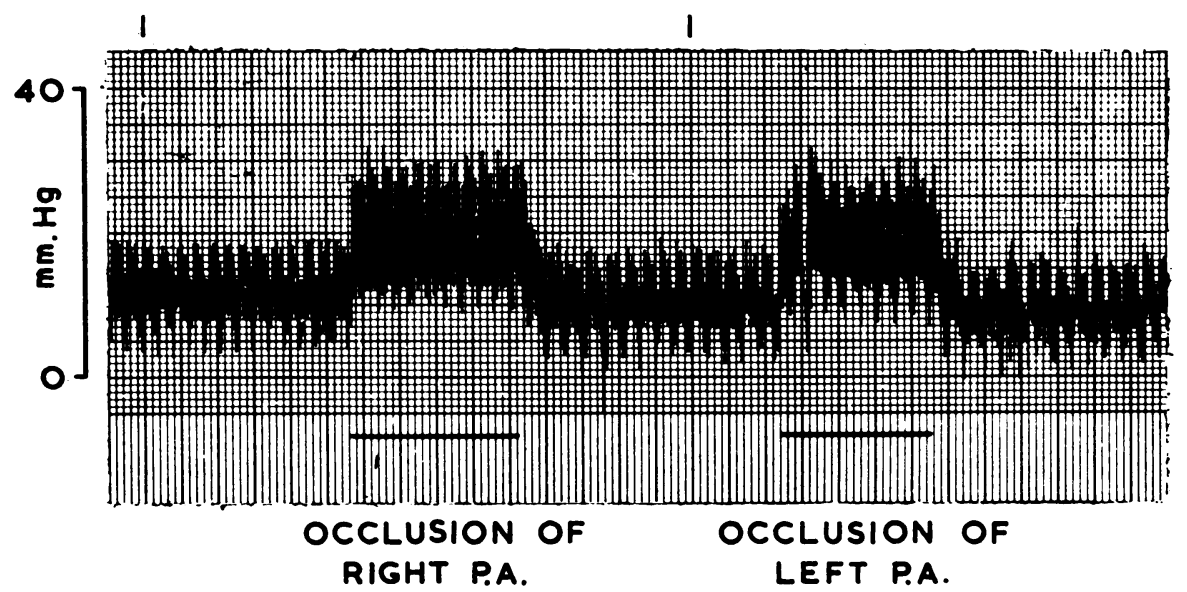

FIG. 12. Exp. T15. Six months after autotransplantation of left lung. Temporary unilateral pulmonary artery occlusion. A normal response to occlusion of the right and left pulmonary arteries with a balloon catheter.
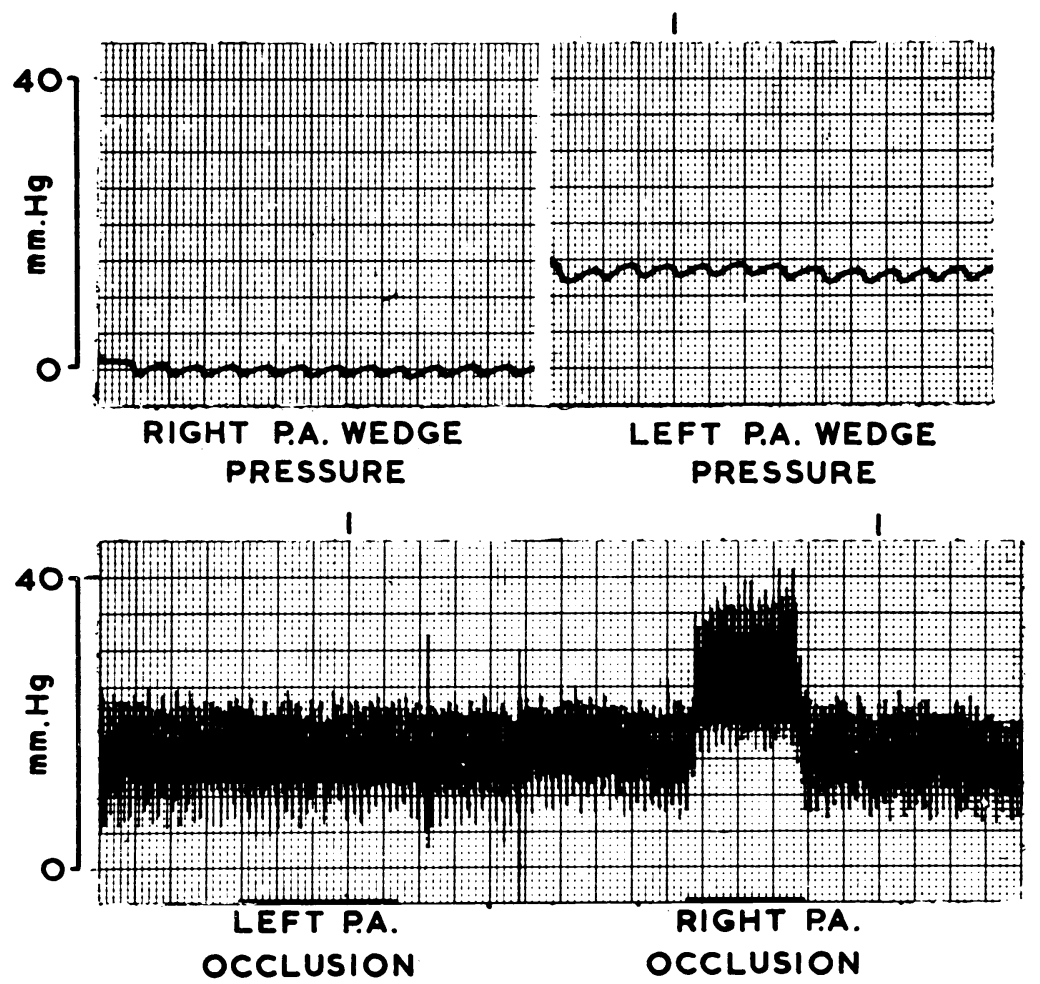

FIG. 13. Exp. T 5, 48-kg. ewe. Twelve months after autotransplantation of left lung. Balloon occlusion of left pulmonary artery produces no rise of pressure; occluding the right branch produces a steep rise in pressure. The reason for this difference is a high wedge pressure on the left side due to obstruction at the venous anastomosis. Most of the pulmonary blood flow is through the right lung. 
measured with the sheep supine and sedated were within the normal range (Table V). When the right and left pulmonary arteries were occluded in turn with a balloon catheter there was in four a normal response, namely a moderate and similar rise of pressure (Fig. 12). In one, however, balloon obstruction of the left pulmonary artery was

TABLE V

RIGHT HEART CATHETERIZATION SIX MONTHS OR MORE AFTER AUTOTRANSPLANTATION OF THE LEFT IUNG

\begin{tabular}{|c|c|c|c|c|c|}
\hline \multirow{2}{*}{ Sheep } & \multirow{2}{*}{$\begin{array}{c}\text { Pulmonary } \\
\text { Arterial } \\
\text { Pressure }\end{array}$} & \multicolumn{2}{|c|}{ Wedge Pressure } & \multicolumn{2}{|c|}{$\begin{array}{l}\text { Balloon Occlusion of } \\
\text { Pulmonary Artery }\end{array}$} \\
\hline & & $\begin{array}{l}\text { Right } \\
\text { Lung }\end{array}$ & $\begin{array}{l}\text { Left } \\
\text { Lung }\end{array}$ & Right & Left \\
\hline T 5 & $\frac{18}{8}-$ & -2 & +12 & $\frac{25}{11} \rightarrow \frac{35}{20}$ & $\frac{25}{10} \rightarrow \frac{25}{10}$ \\
\hline T15 & $\frac{15}{0}$ & +1 & -3 & & \\
\hline $\mathbf{T} 21$ & $\frac{13}{3}(8)$ & -5 & -3 & $\frac{13}{8} \rightarrow \frac{18}{12}$ & $\frac{12}{3} \rightarrow \frac{14}{11}$ \\
\hline $\mathrm{T} 22$ & $\frac{23}{11}(14)$ & 2 & & $\frac{23}{8} \rightarrow \frac{33}{11}$ & $\frac{23}{8} \rightarrow \frac{33}{11}$ \\
\hline T24 & $\frac{13}{3}(8)$ & 0 & 0 & & \\
\hline T28 & $\frac{18}{3}(6)$ & +1 & +1 & $3 \rightarrow 21$ & $3 \rightarrow 21$ \\
\hline T38 & $\frac{31}{8}(15)$ & +1 & 0 & $6 \rightarrow 25$ & $13 \rightarrow 16$ \\
\hline T39 & $\frac{20}{8}(13)$ & +4 & +11 & $7 \rightarrow 24$ & $6 \rightarrow 17$ \\
\hline $\mathrm{T} 46$ & $\frac{18}{-7}-$ & -2 & -1 & $6 \rightarrow 16$ & $6 \rightarrow 17$ \\
\hline
\end{tabular}

The zero reference point is $10 \mathrm{~cm}$. below the sternum with the animals in the supine position. The pressures are in $\mathbf{m m} . \mathbf{H g}$; in some experiments the effect of a balloon occlusion was studied while recording the mean pulmonary arterial pressure.

tolerated without a rise of pressure, while obstruction of the right with diversion of the whole pulmonary blood flow into the autograft caused a sharp rise in pressure (Fig. 13). There were two other sheep in which the response was intermediate with a larger rise of pressure when the right pulmonary artery was occluded.

Wedge pressures were recorded from right and left lower lobes for comparison. In two there was a difference of 6 and $14 \mathrm{~mm}$. $\mathrm{Hg}$ respectively, and this indicated obstruction between the tip of the catheter in the left lung and the left atrium. The two sheep in which this difference in wedge pressures was recorded showed the most abnormal response to balloon occlusion.
These results could be explained as another manifestation of pulmonary venous obstruction with stenosis at the suture line severe enough to divert blood into the right lung, and this preferential flow could account for the diminished oxygen uptake in the autograft.

Some confirmation of this thesis was obtained post mortem. Figure 14 shows the left atrium of the sheep whose angiogram is shown in Figure 11. and the effects of balloon occlusion are seen in Figure 13. The left superior pulmonary vein has

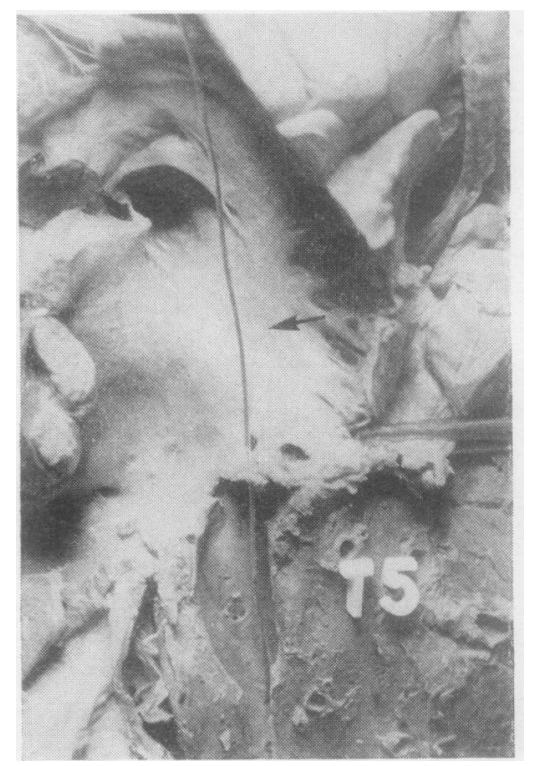

FIG. 14. Left atrium of a sheep which died of unrelated 3 disease 20 months after operation. The superior pulmonary $\dot{8}$ vein is occluded (see arrow) and the inferior vein is severely stenosed at its entry into the left atrium (marked by probe).

been completely occluded and the orifice of the $\frac{D}{2}$ inferior vein is severely stenosed. Oxygen uptake $N$ of the left lung was only $20 \%$, but the ventilation $\Omega$ was $45 \%$.

\section{DISCUSSION}

Post-mortem examination of the sheep which died $\stackrel{\odot}{\overparen{D}}$ after autotransplantation of the left lung confirms $\stackrel{D}{\rightarrow}$ the experience of other workers (Haglin, Telander, 0 Muzzall, Kiser, and Strobel, 1963 ; Blumenstock ơ and Kahn, 1961 ; Linberg, Demetriades, Arm- $\mathbb{\cap}$ strong, and Konsuwan, 1961) that the left atrial $\mathbb{\Phi}$ anastomosis is the crucial part of this operation. Significant narrowing or obstruction usually 
produces pulmonary oedema and death from asphyxia. Thrombus formation at the suture line certainly contributes to obstruction and occurs despite heparin given just before the lung is excised. We considered giving further doses of heparin in the immediate post-operative period, but a review of our post-mortem findings showed no important obstruction by thrombus except as a complication of severe surgical narrowing. It seems probable that thrombosis also occurred at the left atrial suture line in the survivors, but if so we have no evidence that it affects the longterm result.

It is easy to see this mechanical basis for pulmonary oedema but difficult to understand how obstruction may occur without oedema. In four of our six late post-operative deaths there was severe pulmonary venous obstruction, yet the clinical picture was of fatal pulmonary sepsis weeks later (Fig. 5). Moreover in three other sheep which died of unrelated causes the pulmonary vein from the left upper lobe was found to be completely obstructed (Fig. 4b), yet in each the lobe appeared normal and could be inflated normally. One of these sheep was a 20 months survivor which had avoided pulmonary sepsis for a considerable period as well as pulmonary oedema. A similar post-mortem finding has been reported by Portin, Rasmussen, Stewart, and Andersen (1960) in a dog sacrificed 35 months after successful reimplantation. We have as yet no explanation of this apparent immunity from pulmonary oedema, but the histological findings are being reported separately. Certainly the pulmonary artery branch to the left upper lobe was patent in the one sheep in which we performed post-mortem arterial and venous angiography (Fig. 15).

When we measured by bronchospirometry the function of our autografts six months after operation the results were similar to those reported by many other workers, namely ventilation normal or nearly normal with oxygen uptake more variable and sometimes markedly reduced. Carbon dioxide exchange has been reported to parallel the oxygen uptake measurements (Nigro, Evans, Gago, and Adams, 1964). This pattern of function in the reimplanted lung has been variously attributed to loss of innervation with spasm of the pulmonary arteries (Nigro et al., 1964), a diffusion defect in the alveolar capillary membrane (Reemtsma et al., 1963), bronchial stenosis (Yeh, Ellison, and Ellison, 1962), increased pulmonary vascular resistance (Amirana, Rohman, Oka, Kikkawa, Gueft, and State, 1964), and division of

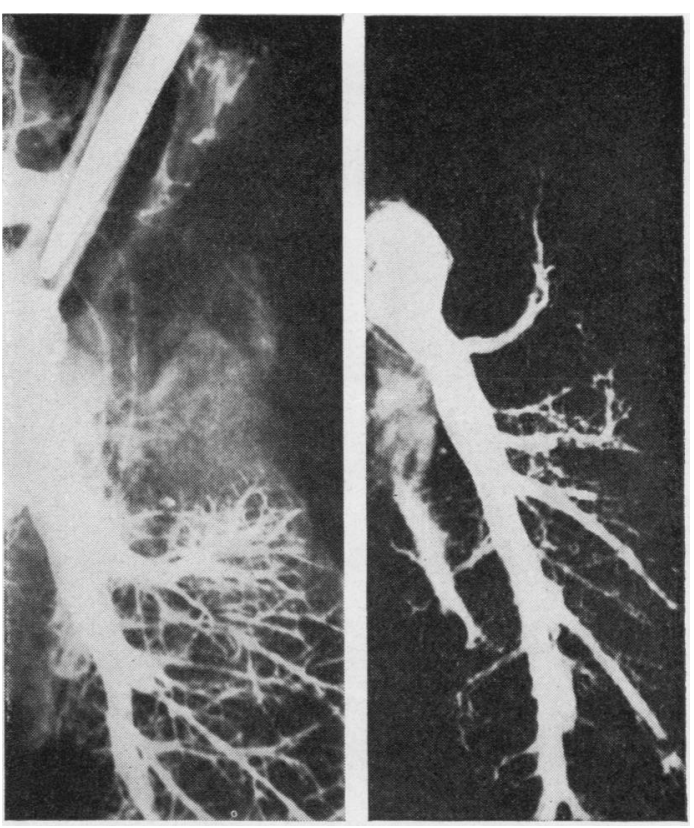

FIG. 15. Post-mortem pulmonary venous and pulmonxry arterial angiograms of a sheep which died of an accidental anaesthetic mishap six months after operation. The superior pulmonary vein is completely occluded but the pulmonary artery branch to the upper lobe is patent.

the vagal nerve fibres (Hardy et al., 1963a), and there has been speculation about the effects of interruption of the bronchial artery supply and lymphatic drainage.

We wondered initially if irreversible anoxic damage was being produced in the autograft during the time taken to reimplant it and reestablish the circulation, particularly since we had never taken measures to protect the lung from these changes. In our series the time taken to reimplant the lung varied from $55 \mathrm{~min}$. to $120 \mathrm{~min}$. with a mean of 85 minutes. In a few experiments we examined samples of pulmonary venous blood from the autograft at intervals during reimplantation. Figure 16 shows a typical result, and the acidosis and $\mathrm{K}^{+}$release confirm the expected severity of the effects of prolonged circulatory arrest. While Borrie (1962) has demonstrated that the left lung of the sheep can regularly withstand two and a half hours of anoxia, and our results confirm this, there must nevertheless be some damage to the lung parenchyma during this period. We could not find any correlation between the duration of anoxia in our sheep and the later measurements of autograft function. Still, this is 


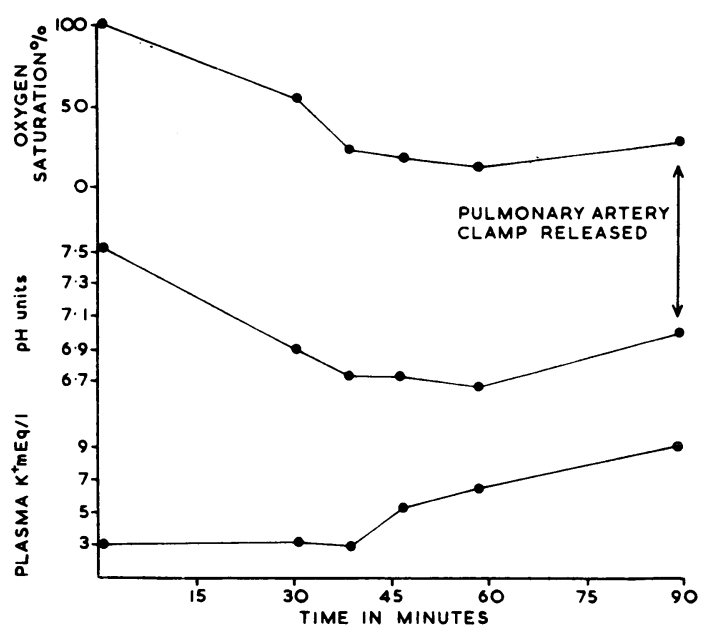

FIG. 16. $\mathrm{O}_{2}$ saturation, $\mathrm{pH}$ and plasma $\mathrm{K}^{+}$levels in pulmonary venous blood sampled from the autograft during reimplantation.

a possible explanation of the initial depressed function, followed by an improvement which has been found when these measurements are made immediately post-operatively (Reemtsma et al., 1963).

The idea that the reduction in oxygen uptake was due to a reduction or diversion of blood flow was first suggested when we reviewed the results of a preliminary experiment. In this sheep the pulmonary vein from the left lower lobe had been divided and repaired with a continuous suture; marked narrowing had been produced; no other structure had been divided. Bronchospirometry subsequently showed greatly diminished oxygen uptake with ventilation well maintained. When angiography in some of our long-term survivors showed a small left and a large right pulmonary artery this suggested that the pulmonary blood flow was now preferentially into the unoperated lung and we considered whether this could be due to a degree of pulmonary venous obstruction. In two of our animals the wedge pressures were different enough to support this view, and in these balloon occlusion of the right and left pulmonary arteries caused a different response, as might be expected. In one of these necropsy showed an occluded left superior pulmonary vein and severe stenosis at the entry of the inferior vein into the left atrium ; just the sort of thing indeed to divert the blood flow into the normal lung. Attempts to illustrate the anatomy at the left atrial suture line in life have not been successful. This complication of venous obstruction is probably particularly inherent in autotransplantation, where there is never quite enough tissue for suturing: in homotransplantation it should be less of a problem.

We have not as yet tested autograft function in our survivors by ligation of the right pulmonary artery. This is a final but rather crude test of function and it should be possible to predict the result from the measurements we already have. It might be more informative to study function over a period of some years by the tests already described. In so far as pregnancy is a test of pulmonary function our survivors have passed this well; nearly all have lambed, some for a second time, and some have produced twins.

Division and repair of the left pulmonary artery has not given rise to difficulty. In one instance the use of an incorrect clamp tore the vessel and caused fatal haemorrhage. A degree of narrowing is frequent here as well, but there has been no important obstruction or pressure gradient, and flow does not seem to have been affected. Thrombotic occlusion has been reported as a complication (Haglin et al., 1963) and we have found small thrombi post mortem in some animals which died shortly after operation, but these were never large enough to have caused obstruction.

Bronchial stenosis has been reported as a complication in dogs by Duvoisin, Fowler, Payne, and Ellis (1964), Yeh et al. (1962), Haglin et al. (1963), and Gago, Delgado, Archer, Schoenfeld, Ranniger, Nigro, and Adams (1964); we have not found this, perhaps the larger size of the sheep is an advantage (Fig. 17). Bronchograms in six survivors show the site of the suture line but no stenosis (Fig. 18); in many others a Carlens catheter has been passed into the left main bronchus without undue difficulty and we have not found this complication post mortem.

In addition to these three major structures, three others are destroyed or divided by this operation. Borrie and Lichter (1964) have shown that division of the bronchial artery to a lung produces no measurable change in lung function, and our experiments largely confirm this.

It seems likely that the re-establishment of the lymphatic drainage which has been shown to occur in the second and third post-operative weeks in the dog (Hardy et al., 1963a) also takes place in the sheep, but we have no direct information on this.

As far as the nerve pathways are concerned, our findings will be included in a separate report on the histological appearances of the autotransplanted lung. 


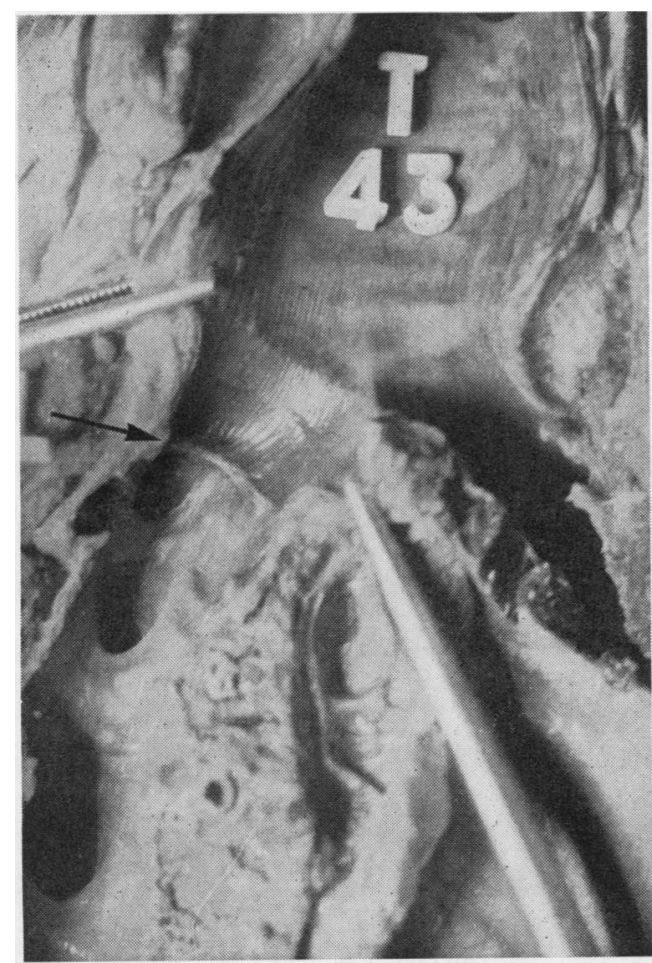

FIG. 17. The site of bronchial anastomosis eight months after operation.

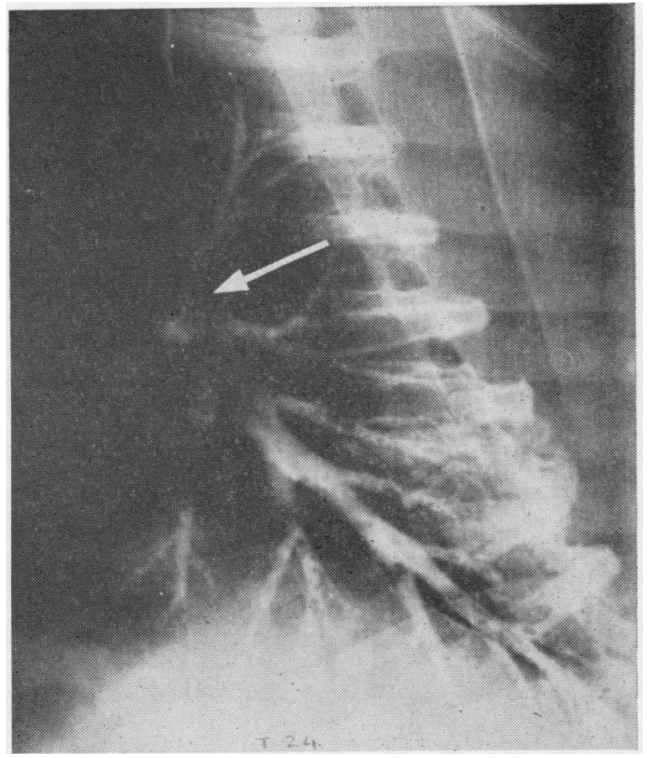

FIG. 18. A lateral bronchogram of the left lung showing a normal tree and suture line (arrow).
We thought that, for various reasons, autografts might be particularly liable to infection. In this respect our long-term survivors probably had a more severe test than most of the other animals in which lung autotransplantation has been reported. Within a week or two they were discharged to join the rest of the flock and led a completely out-of-doors existence in all weathers, but infection has only been seen as a complication of pulmonary venous obstruction.

\section{SUMMARY}

Autotransplantation of the left lung was performed in 40 sheep with the aim of studying the technical problems of transplantation and the late autograft function. The time taken to reimplant and re-establish the circulation varied from 55 to $120 \mathrm{~min}$. (mean $85 \mathrm{~min}$.) and no special measures were taken to protect the lung from anoxic damage.

There were three operative deaths, but the early post-operative mortality was heavy (42\%): the main cause of this was pulmonary venous obstruction. This caused pulmonary oedema, and death was usual within six hours. The anatomy of the pulmonary veins in these animals was best demonstrated by post-mortem angiography from the left atrium.

The late post-operative mortality, between one and three months, was $15 \%$, and again the main cause was pulmonary venous obstruction. The clinical picture was now different. Pulmonary sepsis was the presenting feature.

In 14 sheep $(35 \%)$ the period of survival so far ranges from two to 20 months. The state of function in the autograft was assessed by radiography, bronchospirometry, bronchography, right heart catheterization, and angiography. In this group there was little difference in measurements of ventilation in the two lungs, but the oxygen uptake results varied from $20 \%$ to $50 \%$, with a mean of $41 \%$.

In those survivors in which oxygen uptake was reduced there was evidence that this resulted from changes in the pulmonary circulation. This seemed to be due to a degree of stenosis at the left atrial suture line leading to preferential blood flow into the right lung.

The normal results in some of these long-term survivors indicated that pulmonary venous obstruction was not inevitable, and further that removal of the bronchial artery supply, division of nerve pathways, and interruption of lymphatic drainage have no long-term effects on the func- 
tion of the autograft in so far as we can measure it.

We are grateful to Dr. Leo Steinhart for the left atrial angiograms, to Mr. F. E. Bull, B.Sc., for biochemical investigations, to Mr. F. Midgeley, A.I.I.P., for the photography, and to many junior staff who assisted at the operations.

\section{REFERENCES}

A mirana, M. T., Rohman, M., Oka, M., Kikkawa, Y., Gueft, B., and State, D. (1964). Functional and pathologic changes in the reimplanted lung. Surg. Forum, 15, 177.

Elumenstock, D. A., and Kahn, D. R. (1961). Replantation and trans plantation of the canine lung. J. surg. Res., 1,40 .

Borrie, J. (1962). Tolerance time of sheep lungs to anoxia. Proc. Univ. Otago med. Sch., 40, 5.

- and Lichter, I. (1964). Lung transplantation: technical problems. Thorax, 19, 383.

Demikhov, V.P.(1962). Experimental Transplantation of Vital Organs, trans. B. Haigh. Consultants Bureau, New York.

Duvoisin, G. E., Fowler, W. S., Payne, W. S., and Ellis, F. H. (1964) Reimplantation of the dog lung with survival after contralatera pneumonectomy. Surg. Forum, 15, 173

Gago, O., Delgado, E., Archer, F. L., Schoenfeld, F. G., Ranniger, K. Nigro, S. L., and Adams, W. E. (1964). Homotransplantation and autotransplantation of a pulmonary lobe. J. thorac. cardiovasc Surg., 48, 726.
Haglin, J., Telander, R. L., Muzzall, R. E., Kiser, J. C., and Strobel, C. J. (1963). Comparison of lung autotransplantation in the primate and dog. Surg. Forum, 14, 196.

Hardy, J. D., Eraslan, S., and Dalton, M. L. (1963a). Autotransplantation and homotransplantation of the lung: further studies. J. thorac. cardiovasc. Surg., 46,606. Webb, W. R., Dalton, M. L., and Walker, G. R. (1963b). Lung homotransplantation in man. Report of the initial case. J. Amer. med. Ass., 186, 1065 .

Juvenelle, A. A., Citret, C., Wiles, C. E., and Stewart, J. D. (1951). Pneumonectomy with replantation of the lung in the dog for physiologic study. J. thorac. Surg., 21, 111.

Linberg, E. J., Demetriades, A., Armstrong, B. W., and Konsuwan, N. (1961). Lung reimplantation in the dog. J. Amer. med. Ass., 178, 486.

Magovern, G. J., and Yates, A. J. (1964). Human homotransplantation of left lung: report of a case. Ann. N.Y. Acad. Sci., 120, 710.

Nigro, S. I., Evans, R. H., Gago, O., and Adams, W. E. (1964). Altered physiology of the pulmonary vascular bed. A factor in decreased function of the reimplanted lung. Dis. Chest, 46, 317.

Portin, B. A Rasmussen, G. L. Stewart, J. D. and Andersen, M. N. (1960). Physiologic and anatomic studies thirty-five months after successful replantation of the lung. J. thorac. Surg., 39, 380 .

Reemtsma, K., Rogers, R. E., Lucas, J. F., Schmidt, F. E., and Davis, F. H. (1963). Studies of pulmonary function in transplantation of the canine lung. J. thorac. cardiovasc. Surg., 46, 589.

Staudacher, V. E., Bellinazzo, P., and Pulin, A. (1950). Primi rilievi su tentativi di reimplanti autoplastici e di trapianti omoplastici di lobi polmonari. Chirurgia (Milano), 5, 223 (Int. Abst. Surg. 1951, 93, 236).

Yeh, T. J., Ellison, L. T., and Ellison, R. G. (1962). Functional evaluation of the autotransplanted lung in the dog. Amer. Rev. resp. Dis., 86, 791 . 